Erdoğan S., Kaya M.

\title{
Yön Faktörü Bdelloid Biyoçeşitliliğini Etkiler Mi?
}

\author{
Sevil ERDOĞAN*,1, Murat KAYA ${ }^{2}$ \\ ${ }^{1}$ Trakya Universitesi, Keşan Meslek Yüksekokulu, Su Ürünleri Programı, 22800 Keşan, Edirne-TÜRKIYE \\ ${ }^{2}$ Aksaray Universitesi, Fen Edebiyat Fakültesi, Biyoteknoloji ve Moleküler Biyoloji Bölümü, \\ 68100 Aksaray-TÜRKIYE
}

Özet

$\mathrm{Bu}$ çalışmada mikroorganizların dağılım modellerinin belirlenmesine yönelik çalışmalara katkı sağlamak amacıyla ana yönlerin bdelloid rotifer türlerinin dağılımı üzerine etkili olup olmadığı araştırılmışıı. Bu amaçla Tortula ruralis ile kaplı bir duvarın doğu, kuzey ve üst kısmından toplanan $10 \mathrm{~cm}^{2}$ lik yosun örnekleri üzerindeki bidelloid rotiferlerin tür kompozisyonu ve bolluğu incelenmiştir. Kuzey yönünün diğer yönlere göre daha fazla birey bolluğuna sahip olduğu görülmüştür. Bu çalışma tür kompozisyonu ve bdelloid birey bolluğunun yönlere göre farklılıklar gösterdiğini ve bdelloid rotiferlerin habitat seçimi gösterebileceklerini ortaya koymaktadır.

Anahtar Kelimeler: Ana yönler, yosun, tür zenginliği, bolluk, habitat tercihi.

\section{Do Cardinal Directions Affect the Diversity of Bdelloid Rotifers?}

\section{Abstract}

In this study, we investigated whether cardinal directions affect the distribution of bdelloid rotifers or not, in order to contribute to the studies will be carried out determining the distribution patterns of microorganisms. Thus, we examined species composition and abundance of bdelloid rotifers living on $10 \mathrm{~cm}^{2}$ of lichen samples which was collected from the east and north sides and from top of a wall covered with Tortula ruralis (moss). The North side of the wall had the highest abundance. The results showed that species composition and abundance of bdelloid rotifers are affected by different cardinal directions and bdelloid rotifers may have an habitat preferency.

Keywords: Cardinal directions, moss, species richness, abundance, habitat choice.

\footnotetext{
*e-mail: serdogantrakya@gmail.com
} 


\section{Giriş}

Organizmaların yeryüzündeki dağılışının nedenlerini anlamaya yönelik olarak günümüze kadar gelen süreçte çok sayıda çalışmalar yapılmış olup bu çalışmaların çoğunluğu makroorganizmalar üzerine yoğunlaşmış ve makroorganizmalar için biyocoğrafik dağllım modelleri belirlenmiştir. Mikroorganizmaların da makroorganizmalara benzer bir biyocoğrafik dağılım gösterip göstermediği sorusu günümüz bilim adamlarının cevap bulmaya çalıştığı sorulardan biridir. Gelişen teknoloji ve yeni metodların yaygınlaşmasına bağlı olarak mikrorganizmalar üzerine yapılan çalışmaların sayısı artmış ve bu soruya cevap vermek amacıyla birçok çalışma yapılmıştır [1-2-3-4-5-6].

Fenchel ve Finlay [1] biyocoğrafik mesafenin mikroorganizmaların dağılımını sınırlamadığını, $2 \mathrm{~mm}$ den kü̧̈ük mikroorganizmaların her yerde dağılım gösterme eğiliminde olduklarını öne sürmüşler ve "ubiquity" (everything is everywhere) hipotezini ortaya atmışlardır. Bu görüşün geçerliliğini savunan çalışmalar çok olmakla birlikte [7 ve 8], bazı çalışmalarda mikroorganizmaların da bir dağılım modeline sahip olduğu belirtilmektedir [2-6-9-10].

$\mathrm{Bu}$ güne kadar yapılan çalışmalarda çoğunlukla bakteriler ve protozoalar model alınarak mikroorganizmaların dağılımı hakkında bazı bilgiler edinilmiştir. Mikroskobik boyutta olması ve yeryüzünde geniş dağılım göstermesi nedeniyle mikroorganizmaların dağ 1 lım modelini belirlemek için model olarak kullanılabilecek bir diğer canlı grubu da bdelloid rotiferlerdir.

Bdelloid rotiferler 100-2000 $\mu \mathrm{m}$ [11] arasında değişen büyüklüğe sahip mikroorganizmalardır. Sucul ve karasal habitatlarda yaşam sürerler ve olumsuz çevresel şartları atlatabilmek için anhidrobiosis olarak adlandırılan dormansi haline geçerler [12].

$\mathrm{Bu}$ nedenle bu çalışmada bir yosun türü olan Tortula ruralis ile kaplı bir duvarın üzerinde yaşayan bdelloid rotiferlerin dağılımı üzerine habitat sıcaklığı ve nemliliğini etkileyen ana yönlerin etkili olup olmadığı araştırılmıştır.

\section{Materyal ve Metot}

Bu çalışmada 28.10.2012 tarihinde Gelibolu'dan genişliği $3 \mathrm{~m}$ ye $50 \mathrm{~cm}$ olan ve Tortula ruralis ile kaph bir duvarın $\left(40^{\circ} 24^{\prime} 36.08^{\prime \prime} \mathrm{K}\right.$; 26² $\left.40^{\prime} 47.63^{\prime \prime} \mathrm{D}\right)$ üzerinden kuzey, doğu ve duvarın üst tarafı olmak üzere 3 farklı yönden 10 'ar $\mathrm{cm}^{2}$ lik yosun örnekleri toplanmıştır. Tortula ruralis kalkerli topraklar üzerinde daha iyi gelişim gösteren, $4 \mathrm{~cm}$ boya ulaşabilen dik saplı bir yosundur. Islandığında parlak yeşil ve yaprakları gevşektir. Kuruduğunda ise yapraklar sapın etrafına sarılır ve kırmızı kahverengi bir renk alır. Bu yosun çok çeşitli miktarda güneş ışığını tolere edebilir. Kuru halde yıllarca dormansi formunda kalabilir ve daha sonra metobolik faaliyetlerini gerçekleştirmek üzere tekrar aktif hale gelebilir. $\mathrm{Bu}$ özelliklerinden dolayı Tortula ruralis bdelloid rotiferler için elverişli bir habitat oluşturmaktadır. Kağı̆t zarflar içerisinde laboratuvara getirilen yosun örnekleri üzerindeki bdelloid rotiferlerin dormansi formundan çıkmalarını sağlamak için içerisinde distile su bulunan petri kaplarında bekletilmiştir. Yaklaşık 1-2 saat kadar sonra dormansi formundan çıkan ve aktif hale gelen bdelloid rotiferler canlı olarak Leica marka inverted mikroskop altında incelenmiştir. Yosun örnekleri içerisindeki tüm canlı bdelloid rotifer bireyleri sayılmıştır. Tür teşhisleri Donner [11], Bartos [13], Kutikova [14], Ricci ve Fontaneto [15] kaynakları kullanılarak Leica DM 3000 marka binoküler mikroskobu altında yapılmıştır. 
Duvarın üç farklı yönünde bulunan Tortula ruralis üzerindeki bdelloid tür çeşitliliğinin yönlere göre benzer olup olmadıkları Jaccard benzerlik indeksi ile analiz edildi [16].

Yosun üzerinde yaşayan bdelloid rotiferlerin yönlere göre dağılımlarını ve tür kompozisyonundaki varyasyon patternini belirlemek amaciyla PCA (Principal Components Analysis) analizi uygulanmıştır. Görülme sıklığı bir kez olan türler analize dahil edilmemiştir. Analizden önce ham veriye logaritmik dönüşüm uygulanmıştır.

Analiz için CANOCO v. 4.5 paket program kullanılmıştır [17].

\section{Sonuç ve Tartışma}

Yosun örneklerinin incelenmesi sonucunda Macrotrachela cinsine ait 8 tür, Habrotrocha cinsine ait 6 tür, Mniobia ve Philodina cinslerine ait 4'er tür ve Adineta, Ceratotrocha, Rotaria cinslerine ait 1'er tür olmak üzere toplam 25 takson tespit edilmiştir (Tablo 1). Dokuz taksonun teşhisinde tür düzeyine inilememiştir. Bdelloid rotiferler tür içerisinde dahi oldukça fazla varyasyon göstermektedir. Bu nedenle tür seviyesinde teşhis için bazen morfolojik karakterler yeterli olmamakta ve moleküler analizlere ihtiyaç duyulmaktadır.

Tablo 1. Teşhis edilen Bdelloid rotifer türlerinin listesi ve yönlere göre dağılımı.

\begin{tabular}{|c|c|c|c|}
\hline Bdelloid Rotifer Türleri & Duvar üzeri & Kuzey & Doğu \\
\hline Adineta vaga (Davis, 1873) & + & + & + \\
\hline Ceratotrocha cornigera (Bryce, 1893) & - & - & + \\
\hline Habrotrocha bidens (Gosse, 1851) & - & + & + \\
\hline H. constricta (Dujardin, 1841) & + & - & - \\
\hline H. pusilla (Bryce, 1893) & - & + & + \\
\hline Habrotrocha sp.1 & + & - & - \\
\hline Habrotrocha sp.2 & + & - & - \\
\hline Habrotrocha sp. 3 & - & - & + \\
\hline Macrotrachela aculeata Milne, 1886 & - & + & + \\
\hline M. ehrenbergii (Janson, 1893) & + & + & - \\
\hline M. habita (Bryce, 1894) & + & - & - \\
\hline M. nana (Bryce, 1912) & - & + & - \\
\hline M. papillosa Thompson, 1892 & + & - & + \\
\hline Macrotrachela sp.1 & + & + & - \\
\hline Macrotrachela sp. 2 & + & - & - \\
\hline Macrotrachela sp.3 & - & + & - \\
\hline Mniobia bredensis De Koning, 1947 & - & + & + \\
\hline M. russeola (Zelinka, 1891) & - & - & + \\
\hline Mniobia sp.1 & - & + & - \\
\hline Mniobia sp.2 & - & + & - \\
\hline Philodina parvicalcar De Koning, 1947 & + & + & - \\
\hline P. plena (Bryce, 1894) & + & - & - \\
\hline P. vorax (Janson, 1893) & + & - & - \\
\hline Philodina sp.1 & + & - & - \\
\hline Rotaria sordida (Western, 1893) & + & + & + \\
\hline
\end{tabular}


Tür zenginliği üç yönde de (duvarın üst kısmı: 14 tür, kuzey: 13 tür, doğu: 10 tür) birbirine benzerken, tür kompozisyonu yönlere göre farklık göstermektedir. Adineta vaga ve Rotaria sordida'ya her üç yönde de rastlanmıştır.

Kuzey yönü toplam 1489 bireyle en fazla bolluğa sahip olurken, duvarın üst kısmı toplam 863 bireyle ikinci sırada yer almış ve Doğu yönü de toplam 510 bireyle en az bolluğa sahip olan yön olmuştur. Duvarın üst kısmında en fazla bolluğa sahip olan A.vaga tüm bireylerin \% 94 ünü oluştururken, Kuzey yönündeki tüm bireylerin \% 51'ini A.vaga, \%15'ini Mniobia bredensis, \%14'ünü Habrotrocha pusilla, \%9'unu Rotaria sordida ve \%8'ini Habrotrocha bidens oluşturmaktadır. Doğu yönünde ise tüm bireylerin \%65'ini A.vaga ve \%14'ünü Macrotrachela aculeata oluşturmuştur.

Bdelloid türlerinin mikrohabitat tiplerine göre dağılımlarının besin, 1şık, sıcaklık, nem, predatörler, pH, oksijen, tuzluluk, gibi faktörlerden etkilendiği daha önceki çalışmalarda ortaya konmuştur [18-19-20-21]. Bu çalışmada Kuzey yönündeki birey bolluğunun diğer yönlerden bariz bir şekilde farklılık gösterdiği görülmektedir. Kuzey yönü direk güneş 1şığına maruz kalmadığından bu yöndeki yosunların nemliliği doğu yönü ve duvarın üst kısmına göre daha fazladır ve yosunların daha iyi gelişmesini sağlar [22]. Bu da bdelloid rotiferlerin hayatta kalma şansını arttırmaktadır.

Adineta vaga her üç yönde de bol olarak bulunmakta ve Doğu yönündeki birey bolluğunun \%94'ünü oluşturmaktadır. Watanabe [23] canlıların vücuttan buharlaşan su miktarını kontrol etmek için geliştirdikleri fiziksel, davranışsal, fizyolojik ve morfolojik adaptasyonların anhidrobiosis devresinin başarılı bir şekilde atlatılmasını sağladığını ve organizmaların yaşama şansını arttırdığını belirtmektedir. Örstan [24] hızlı bir şekilde kuruyan ve dormansiye giren A. vaga bireylerinin dormansi süresince hayatta kalma oranlarının oldukça yüksek olduğunu belirtmektedir. Bu çalışmada da A. vaga'nın çok sayıda birey içeren bu denli başarılı populasyonlar oluşturmasının nedenlerinden biri türün anhidrobiosis için geliştirdiği adaptasyonlar sonucu olabilir.

Jaccard benzerlik indeksi, tür çeşitliliği bakımından en yüksek benzerliğin Kuzey ve Doğu yönleri arasında olduğunu (\% 35) ortaya koymuştur. Duvar üzeri ve Kuzey yönü arasındaki bdelloid tür kompozisyonu benzerliği \% 23 olarak bulunurken, en düşük tür benzerliğinin (\% 14) duvar üzeri ve Doğu yönü arasında olduğu gözlenmiştir.

Jaccard benzerlik indeksi sonucu farklı yönlerin bdelloid rotifer tür çeşitliliği bakımından benzerliklerinin oldukça az olduğunu ortaya koymuştur. Yönler güneş 1şığını farklı miktarlarda aldığından, farklı yönlerde bulunan yosunların nemlilik oranı da güneş 1şığı miktarına bağlı olarak değişmektedir [22]. Bu da bdelloid rotiferlerin barındığı habitatın özelliklerinin farklılaşmasına yol açmaktadır. Dolayısıyla, bu durum nem ve sıcaklık toleransları farklı olan türlerin farklı yönleri tercih etmesine neden olmakta ve habitatların tür çeşitliliğini etkilemektedir.

Yosun üzerinde yaşayan bdelloid rotiferlerin yönlere göre dağılımlarını ve tür kompozisyonundaki varyasyon modelini belirlemek amaciyla PCA (Principal Components Analysis) analizi uygulanmıştır. Görülme sıklığı 1 kez olan türler analize dahil edilmemiştir. PCA analizinin ilk iki eksenin eigen değerleri sırasıyla 0.484 ve 0.166 olarak bulunmuştur ve ikisi birlikte toplam varyansın \% 65 ini açıklamaktadır.

Şekil 1 H. constricta, Habrotrocha sp.1, Philodina sp.1 ve Macrotrachela habita'nın duvarın üst kısmıyla pozitif ilişkili olduğunu gösterirken, Mniobia sp.1, Mniobia bredensis, H. pusilla, H. bidens 
ve R.sordida ise kuzey yönü ile pozitif ilişki sergilemektedir. Türlerden sadece M.aculeata doğu yönü ile ilişkili görülmektedir.

Fierer [25] bir habitatın çevresel karakterestiklerinden bir veya birkaçının birden taksonların dağılımı üzerinde etkili olabileceğini fakat bunun dağılım modelini etkilemeyeceğini öne sürmektedir. Duvar üzerine düşen 1şık miktarının yönlere göre farklı olabileceğini göz önünde bulundurursak bu durumun yosunun kuruma oranı ve nemlenme kuruma sıcaklığını ve dolayısıyla yosun üzerindeki bdelloid türlerinin hayatta kalma şansını etkilediğini söyleyebiliriz. Bu da nem ve sıcaklık hassasiyetleri farklı olan türlerin farklı yönlerde dağılım göstermesine ve tercih etmesine neden olabilir.

Duvarın direk güneş ışı̆̆ına maruz kalan üst kısmını tercih eden H. constricta, Habrotrocha sp.1, Philodina sp.l ve Macrotrachela habita'nın bu yönde yaşamaya iyi adapte oldukları söylenebilir. Kuzey yönünü tercih eden Mniobia sp.1, Mniobia bredensis, H. pusilla'nın ise farklı ekolojik gereksinimleri olabileceği ve bu nedenle nemli ve direk güneş almayan kuzey yönünü tercih ettikleri söylenebilir.

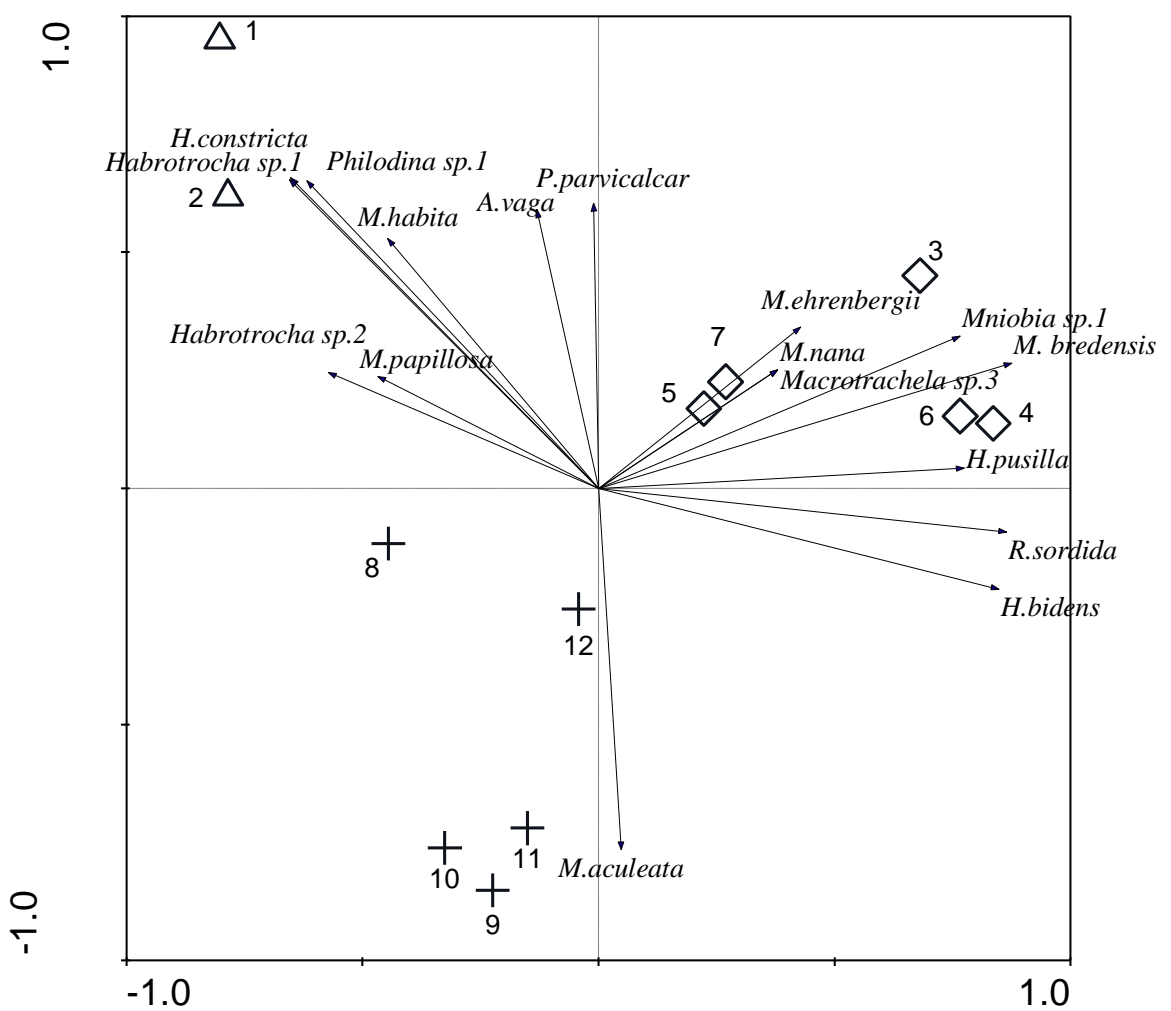

Şekil 1. Bdelloid rotifer türünün yönlere göre dağılımını gösteren PCA ordinasyon grafiği. Okların uzunluğu varyasyonun gücünü göstermektedir.( $\diamond$ : North, +: East, $\Delta$ : Top of the wall)

Sonuç olarak, bu çalışmayla bdelloid rotiferlerin dağılımı üzerine ana yönlerin etkili olup olmadığ1 araştırılmıştır. Tür kompozisyonu ve birey bolluğunun yönlere göre farklı olduğu görülmüştür. Kuzey yönünün diğer yönlerden oldukça fazla birey bolluğunu desteklediği tespit edilmiştir. Bazı bdelloid türlerinin yön tercihi gösterdiği görülmüştür. Bdelloid rotiferlerin yön tercihlerinin habitatların tür dağılımını etkileyen çevresel faktörlerden mi yoksa bdelloid rotiferlerin bir dağılım modeli sergilemesinden mi kaynaklandığını tespit etmek için bu konuda daha çok çalışma yapılması gerekmektedir. 


\section{Kaynaklar}

[1] Fenchel T., Finlay B.J., "The ubiquity of small species: patterns of local and global diversity" Biological Sciences, 54: 777-784, 2004.

[2] Fontaneto D., Ficetola G.F., Ambrosini R., Ricci C., "Patterns of diversity in microscopic animals: are they comparable to those in protists or in larger animals?" Global Ecology Biogeography, 15: 153-162, 2006.

[3] Bryant J.A., Lamanna C., Morlon H., Kerkhoff A.J., Enquis B.J., Green J.L., "Microbes on mountainsides: contrasting elevational patterns of bacterial and plant diversity" Proceedings of the National Academy of Sciences (PNAS), 105: 11505-11511, 2008.

[4] Kaya M., Herniou E., Barraclough T., Fontaneto D., “A faunistic survey of bdelloid rotifers in Turkey” Zoology in the Middle East, 48: 114-116, 2009.

[5] Kaya M., De Smet, W.H., Fontaneto D., "Survey of moss-dwelling bdelloid rotifers from middle Arctic Spitsbergen (Svalbard)” Polar Biology, 33: 833-842, 2010.

[6] Azovsky A., Mazei, Y., "Do microbes have macroecology? Large-scale patterns in the diversity and distribution of marine benthic ciliates" Global Ecology and Biogeography, 22: 163-172, 2013.

[7] Finlay B.J., "Global dispersal of free-living microbial eukaryote species" Science, 296: 10611063, 2002.

[8] Foissner W., "Biogeography and Dispersal of Micro-organisms: A Review Emphasizing Protists" Acta Protozoologica, 45: 111 - 136, 2006.

[9] Vanormelingen P., Verleyen E., Vyverman W., "The diversity and distribution of diatoms: from cosmopolitanism to narrow endemism” Biodiversity Conservation, 17: 393-405, 2008.

[10] Fontaneto D., Westberg M., Hortal J., "Evidence of Weak Habitat Specialisation in Microscopic Animals" PLoS ONE 6(8): e23969. doi:10, 2011.

[11] Donner J., "Ordnung Bdelloidea (Rotatoria, Radertiere)” Akademie Verlag, Berlin: 1-297, 1965.

[12] Tunnacliffe A., Lapinski J., "Resurrecting Van Leeuwetihoek's rotifers: a reappraisal of the role of disaccharides in anhydrobiosis" Philosophical Transaction of the Royal Society London B, 358: 1755-1771, 2003.

[13] Bartos E., The "Czechoslovak Rotatoria of the Order Bdelloidea" Věstník Československé společnosti zoologické, 15: 241-500, 1951.

[14] Kutikova L.A., "Bdelloid Rotifers of the Fauna of Russia" KMK Scientific Press Ltd, Moskva, 316 pp., 2005.

[15] Ricci C., Fontaneto D., "Fauna Europaea: Rotifera Bdelloidea" Fauna Europaea version 1.3, Www.faunaeur.org, 2007.

[16] Jaccard P., "The distribution of the flora of the alpine zone" New Phytologist, 11: 37-50, 1912.

[17] Ter Braak C.J.F., Smilauer, P., "Reference manual and user's guide to CANOCO for Windows, software for canonical community ordination, version 4.5" Centre for Biometry., Wageningen, The Netherlands, 2002.

[18] Ricci C.N., "Ecology of bdelloids: how to be successful” Hydrobiologia, 147: 117-127, 1987. 
[19] Ricci C.N., "Comparison of five strains of a parthenogenetic species, Macrotrachela quadricornifera (Rotifera, Bdelloidea). 1. Life history traits" Hydrobiologia, 211: 147-155, 1991.

[20] Örstan, A., "Microhabitats and Dispersal Routes of Bdelloid Rotifers” Naturel Sciences, vol. 1, pp. 27-36, 1998.

[21] Örstan, A., "Factors affecting long-term survival of dry bdelloid rotifers: a preliminary study" Hydrobiologia, 387: 327-331, 1998a.

[22] Glime, J.M., "Bryophyte Ecology, Volume 1: Physiological Ecology" http://www.bryoecol.mtu.edu, 2006.

[23] Watanabe, M., “Anhydrobiosis in invertebrates" Applied Entomology and Zoology, 41 (1): 15$31,2006$.

[24] Örstan, A., "Desiccation survival of the eggs of the rotifer Adineta vaga (Davis, 1873)" Hydrobiologia, 313: 373-375, 1995.

[25] Fierer, N., "Microbial biogeography: patterns in microbial diversity across space and time. In: Accessing Uncultivated Microorganisms: from the Environment to Organisms and Genomes and Back”. K. Zengler (editor). ASM Press, Washington DC pgs. 95-115, 2008. 